\title{
PHARMACOKINETIC INTERACTION AFTER ORAL COADMINISTRATION OF CLARITHROMYCIN AND THE TYROSINE KINASE INHIBITOR LAPATINIB IN RATS
}

\author{
AGNIESZKA KARBOWNIK' ${ }^{1}$ JOANNA PORAŻKA ${ }^{1}$, ANNA ŁUCZAK ${ }^{1 *}$, \\ ARTUR TEŻYK ${ }^{2}$, TOMASZ GRABOWSKI ${ }^{3}$, ANNA WOLC $^{4,5}$, \\ EDMUND GRZEŚKOWIAK ${ }^{1}$ and EDYTA SZAŁEK ${ }^{1}$
}

\author{
${ }^{1}$ Department of Clinical Pharmacy and Biopharmacy, Poznan University of Medical Sciences, \\ ul. Św. Marii Magdaleny 14, 61-861 Poznań, Poland \\ ${ }^{2}$ Department of Forensic Medicine, Poznan University of Medical Sciences, \\ ul. Święcickiego 6, 60-781 Poznań, Poland \\ ${ }^{3}$ Polpharma Biologics SA, ul. Trzy lipy 3, 80-172 Gdańsk, Poland \\ ${ }^{4}$ Department of Animal Science, Iowa State University, 239E Kildee Hall, \\ Ames, IA 50011, USA \\ ${ }^{5}$ Hy-Line International, $2583240^{\text {th }}$ Street, Dallas Center, IA 50063, USA
}

\begin{abstract}
Lapatinib is a tyrosine kinase inhibitor used to treat patients with locally advanced or metastatic breast cancer exhibiting overexpression of the human epidermal growth factor receptor 2 (HER2 receptor, ErbB2). Preclinical and clinical studies suggest that lapatinib is mainly metabolized by CYP3A4, therefore the study in an animal model was designed to investigate the pharmacokinetic interaction of lapatinib and clarithromycin, a well-known CYP3A4 inhibitor. The rats were subjected to one of the two study groups: lapatinib + clarithromycin $\left(\mathrm{I}_{\mathrm{Lap}+\mathrm{Clar}} ; \mathrm{n}=6\right)$, and lapatinib + placebo $\left(\mathrm{II}_{\mathrm{Lap}} ; \mathrm{n}=6\right)$. The animals were treated with lapatinib in the oral single dose of $100 \mathrm{mg} / \mathrm{kg}$. The antibiotic was administered orally at a dose of $25 \mathrm{mg} / \mathrm{kg}$. Blood sampling was performed until 30 hours after dosing for pharmacokinetic assays. Plasma concentrations of lapatinib were measured by liquid chromatography-mass spectrometry. The comparison of lapatinib maximum concentration and area under the concentration-time curve in the $\mathrm{I}_{\text {Lap+Clar }}$ with the control group $\mathrm{I}_{\text {Lap }}$ gave the ratios of $1.38(90 \%$ confidence interval $(\mathrm{CI}))(1.14 ; 1.68)$ and $1.16(0.75 ; 1.79)$, respectively. A statistically significant difference between analyzed groups was revealed only for maximum concentration $(p=0.0107)$. Single oral administration of clarithromycin significantly increased the concentration of lapatinib in rats, therefore caution should be taken during concomitant treatment with this macrolide and the tyrosine kinase inhibitor in patients.
\end{abstract}

Keywords: lapatinib, clarithromycin, pharmacokinetics, drug-drug interaction, rats

Tyrosine kinase inhibitors (TKIs) such as imatinib, sunitinib, axitinib, and lapatinib are drugs targeted at specific signaling pathways and cellular receptors which play a key role in oncogenesis $(1$, 2). Lapatinib (Tyverb ${ }^{\circledast}$ ) is used in combination with capecitabine, trastuzumab or an aromatase inhibitor to treat patients with locally advanced or metastatic breast cancer exhibiting overexpression of the tyrosine-protein kinase receptor (HER2) (3). Breast cancer is the most common malignant tumor diagnosed in women both in Europe and in the United States. In 2012, over 1.67 million cases of breast cancers were diagnosed. The breast cancer classified in the second place the most frequent reasons of death among women (4). Lapatinib is intensively metabolized into various oxidized metabolites mainly by CYP3A4 and CYP3A5, with a minimal share of CYP2C19 and CYP2C8. Due to the fact that lapatinib is mostly metabolized by CYP3A4 and this isoenzyme is responsible for the biotransformation of more than a half of drugs metabolized by the cytochrome P450 enzyme system, there is a high risk of drug-drug interactions (DDIs). In consequence of DDIs, the efficacy of the anticancer thera-

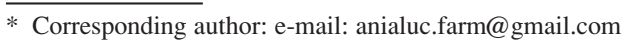


py may be reduced and the complications of the lapatinib therapy may be intensified $(1,2)$. Apart from that, lapatinib is a P-glycoprotein (P-gp) substrate and inhibitor. The inhibitory activity of P-gp may increase the concentration of drugs which are P-gp substrates (5). The risk of adverse reactions to lapatinib increases significantly when the drug is applied in combination with CYP3A4 inhibitors, like clarithromycin, a broadly used macrolide antibiotic. Macrolide antibiotics were conventionally divided into 3 groups according to the interaction potential and the degree of interaction with liver enzymes. The first group is characterized by the strongest capacity to inhibit CYP3A4 activity. It includes erythromycin, which exhibits interactions with: sufentanil, clozapine, cyclosporine, digoxin, felodipine, alprazolam, and lovastatin. The second group, which is characterized by lower affinity to CYP3A4, includes clarithromycin and roxithromycin. The third group includes the macrolides which in practice have no effect on the activity of liver enzymes, e.g. azithromycin $(6,7)$. Clarithromycin exhibits clinically significant interactions with statins (e.g. atorvastatin, lovastatin, simvastatin) (8-10), antidiabetic drugs (e.g. evogliptin) (11), benzodiazepines (e.g. midazolam) (12), immunosuppressants (e.g. tacrolimus (13), everolimus) (14).

Clarithromycin is commonly used in upper respiratory tract infections (e.g., tonsillitis, pharyngitis, rhinosinusitis, otitis media), lower respiratory tract infections (e.g., bronchitis, pneumonia) as well as skin and soft tissue infections. The antibiotic is also applied in combination with omeprazole and amoxicillin to patients with duodenal ulcers and confirmed $H$. pylori infections. Apart from that, clarithromycin is a drug whose new mechanisms of action are still being investigated. Therefore, indications for its use may be broadened in the future. In vitro clarithromycin and thalidomide have a synergistic effect and they decrease the secretion of tumor necrosis factor- $\alpha$ and interleukin- 6 . They inhibit the proliferation of myeloma cells (15). Moreover, clarithromycin is a negative allosteric modulator of GABAA receptors, which might be significant in the treatment of e.g. hypersomnia (16). It is also applied in combination with naproxen and oseltamivir to elderly patients hospitalized due to the severe course of influenza with pneumonia (17). Clarithromycin is a competitive inhibitor of organic anion-transporting polypeptides (OATP) and one of the best-known CYP3A4 inhibitors, which causes a wide range of clinically significant interactions confirmed in vivo. This antibiotic is also a P-gp substrate and a strong competitive inhibitor.
Therefore, its concentration and the resulting CYP3A4 inhibitory activity may be higher when it is simultaneously applied with lapatinib, which is also a P-gp inhibitor (18-22). It is very likely that clarithromycin will be applied to oncological patients treated with lapatinib. The confirmation or exclusion of pharmacokinetic interaction between these drugs provides information about the need to modify the dose of lapatinib.

The aim of the experiment was to assess the influence of clarithromycin on the pharmacokinetics of lapatinib in rats. Rats are very often used in the research model for understanding human diseases and drug interactions (including tyrosine kinase inhibitors), but interspecies differences in terms of CYP3A activity suggest that caution should be applied when extrapolating metabolism data from animal models to humans (23-26).

\section{EXPERIMENTAL}

\section{Reagents}

Lapatinib (CAS number 231277-92-9), methanol, acetonitrile, formic acid, ammonium formate, dimethyl sulfoxide (DMSO) were purchased from Sigma-Aldrich (Poznań, Poland). Erlotinib (CAS number 183321-74-6) was purchased from LGC Standards (Łomianki, Poland). Water used in the mobile phase was deionized, distilled and filtered through a Millipore system before use.

\section{Drugs}

Lapatinib ditosylate monohydrate, equivalent to $250 \mathrm{mg}$ lapatinib (Tyverb ${ }^{\circledR}, 250 \mathrm{mg}$ film-coated tablets, batch number Y68Y) was purchased from Novartis Polska Sp. z o.o., (Warsaw, Poland). Clarithromycin Klacid $^{\circledR} 250 \mathrm{mg} / 5 \mathrm{~mL}$, granules for oral suspension, batch number 1072939) was purchased from Abbott Laboratories Poland Sp. z o.o. (Warsaw, Poland).

\section{Animals}

The experimental protocol for this study was reviewed and approved by the Local Ethics Committee (54/2017). All procedures were performed in accordance with European Union regulations concerning the handling and use of laboratory animals. In order to obtain consistent data, the study was based on the required minimum number of animals and observation time. The laboratory animals included in the study came from Poznan University of Medical Sciences breeding, from the Department of Toxicology on Pharmaceutical Department. Adult male Wistar-strain rats (weight 400-495 g) were 
used in the study. The animals were maintained under standard breeding conditions with a $12 \mathrm{~h}$ light - $12 \mathrm{~h}$ dark cycle (lights on at 06.00 , lights off at $18.00)$ at constant room temperature $\left(23 \pm 2^{\circ} \mathrm{C}\right)$, relative humidity $(55 \% \pm 10 \%)$ and given ad libitum access to food and water. The animals were allowed to acclimatize for a week before beginning the experiment. After acclimatization, the rats were randomly divided into two groups. One group $(n=6)$ received first clarithromycin and next lapatinib $\left(\mathrm{I}_{\text {Lap+Clar }}\right)$, second group $(\mathrm{n}=6)$ received placebo $(0.9 \% \mathrm{NaCl})$ and lapatinib ( $\left.\mathrm{II}_{\text {Lap }}\right)$. Clarithromycin was administrated at a dose of $25 \mathrm{mg}$ per $\mathrm{kg}$ of body weight to the $\mathrm{I}_{\text {Lap+Clar }}$ group $(19,20)$. Lapatinib (100 $\mathrm{mg} / \mathrm{kg}$ ) was dissolved in $1 \mathrm{~mL}$ DMSO (dimethyl sulfoxide) and administered directly into the animal stomach using a gastric probe. In order to make sure that the animals received the entire dose of the drug, $1 \mathrm{~mL}$ of DMSO was then administered to rinse the probe. $80 \mu \mathrm{L}$ of blood was collected from each rat by cutting off a piece of his tail. The blood samples for lapatinib analysis were collected at the following time points: 0, 15, $30 \mathrm{~min}, 1,1.5,2,3,4,6,8,10,24$ and $30 \mathrm{~h}$ (per animal). The blood samples were transferred into heparinized tubes and they were centrifuged at $2880 \mathrm{x} \mathrm{g}$ for $10 \mathrm{~min}$ at $4^{\circ} \mathrm{C}$.

\section{LC-MS/MS assay}

Lapatinib in plasma samples was determined by means of a high performance liquid chromatograph (HPLC) Agilent 1200 Series (Agilent Technologies, Waldbronn, Germany) coupled with an Agilent 6410B triple quadrupole tandem mass spectrometer (Agilent Technologies, Santa Clara, CA, USA), which was a modification of the method developed by Götze L. et al. (27). HPLC separation was carried out at $35^{\circ} \mathrm{C}$ in a Poroshell $120 \mathrm{EC} \mathrm{C} 18$ column $(70 \times 3.0 \mathrm{~mm}, 2.7 \mu \mathrm{m}$, Agilent Technologies, USA). The mobile phase consisted of eluent A $(0.1 \%$ formic acid in water) and eluent $\mathrm{B}(0.1 \%$ formic acid in acetonitrile). The flow rate was set at $500 \mu \mathrm{L} / \mathrm{min}$ and the gradient profile was as follows: 0-2 $\min , 5 \% \mathrm{~B}$; 2-4 min, linear from $5 \%$ to $95 \% \mathrm{~B}$; 4-5 min, $95 \% \mathrm{~B}$; 5-6 min linear from $95 \%$ to $5 \% \mathrm{~B}$; 6-10 min, $5 \% \mathrm{~B}$. The multiple reaction monitoring mode with two transitions for lapatinib and erlotinib (internal standard, IS) was used. Lapatinib was monitored at $\mathrm{m} / \mathrm{z} \quad 581.1 \rightarrow 365.1$ and $581.1 \rightarrow 350.1$, whereas erlotinib at $\mathrm{m} / \mathrm{z} \quad 394.1 \rightarrow 278.1$ and $394.1 \rightarrow 101.1$. An aliquot of rat plasma $(20 \mu \mathrm{L})$ was added to $980 \mu \mathrm{L}$ of methanol containing $5 \mathrm{ng}$ of erlotinib as internal standard and vortexed rigorously, for 30 seconds (total dilution factor 50). After centrifugation, at $10,000 \mathrm{~g}(10 \mathrm{~min})$, the supernatant was transferred into amber glass HPLC vial and injected $(10 \mu \mathrm{L})$ onto the HPLC column. The method was validated according to the European Medicines Agency (EMA) guidelines on bioanalytical method validation (28). During the validation four concentration levels of QC (quality control) samples were analyzed $(0.25 ; 0.5 ; 2500 ; 4000 \mu \mathrm{g} / \mathrm{L})$.

\section{Evaluation of pharmacokinetics}

The pharmacokinetic parameters were estimated with non-compartmental method, using software Phoenix $^{\circledast}$ WinNonlin ${ }^{\circledast}$ 8.1(Certara L.P.). The noncompartmental approach was used for calculations (NCA analysis method). $\mathrm{AUC}_{0-\mathrm{t}}$ - area under the plasma concentration-time curve from zero to the time of the last measurable concentration was calculated using linear trapezoidal rule described by equation: $\mathrm{AUC}_{0-\mathrm{t}}=\left[\left(\mathrm{C}_{\mathrm{n}}+\mathrm{C}_{\mathrm{n}+1}\right) / 2\right] \times \Delta \mathrm{t}$, were $\mathrm{C}_{\mathrm{n}}$ and $\mathrm{C}_{\mathrm{n}+1}$ represents concentration points and related time $\operatorname{span}(\Delta \mathrm{t}) ; \mathrm{AUC}_{0-\infty}-$ area under the plasma concentration-time curve from zero to infinity was calculated using linear trapezoidal rule described by equation: $\left.\mathrm{AUC}_{0 \text {-inf }}=\left[\left(\mathrm{C}_{\mathrm{n}}+\mathrm{C}_{\mathrm{n}+1}\right) / 2\right] \times \Delta \mathrm{t}+\mathrm{C}_{\text {last }} / \mathrm{k}_{\mathrm{el}}\right)$ were $C_{\text {last }}$ is last measurable concentration; $t_{1 / 2 k e l}-$ elimination half-life was calculated using equation: $\mathrm{t}_{1 / 2 \mathrm{kel}}=\ln (2) / \mathrm{k}_{\mathrm{el}} ; \mathrm{k}_{\mathrm{el}}$ - elimination rate constant was determined from the slope of log-transformed raw data by a linear equation, curve fitting was performed using the method of least squares; $\mathrm{Cl} / \mathrm{F}$ clearance was calculated using equation: $\mathrm{CL}=$ $\mathrm{D} / \mathrm{AUC}_{0 \text {-inf }}$ where $\mathrm{D}$ represents dose value; $\mathrm{V}_{\mathrm{d} / \mathrm{F}}-$ volume of distribution was calculated using equation: $\mathrm{V}_{\mathrm{d} / \mathrm{F}}=\left(\mathrm{D} \times \mathrm{AUMC}_{0 \text {-inf }}\right) / \mathrm{AUC}_{0 \text {-inf }}^{2} ; \mathrm{C}_{\text {max }}-$ maximum plasma concentration was observed value; $t_{\max }$ - time necessary to reach the maximum concentration was observed value; $\mathrm{MRT}_{0-\mathrm{t}}-$ mean residence time based on data between zero and the time for the last observed concentration was calculated from equation: $\mathrm{MRT}_{0-\mathrm{t}}=\mathrm{AUMC}_{0-\mathrm{t}} / \mathrm{AUC}_{0-\mathrm{t}} ; \mathrm{AUMC}_{0-\mathrm{t}}-$ area under the first moment curve from zero to the time of the last measurable concentration was calculated using linear trapezoidal rule with equation: $\mathrm{AUMC}_{0-\mathrm{t}}=\left[\left(\mathrm{t}_{\mathrm{n}} \times \mathrm{C}_{\mathrm{n}}+\mathrm{t}_{\mathrm{n}+1} \times \mathrm{C}_{\mathrm{n}+1}\right) / 2\right] \times \Delta \mathrm{t} ; \mathrm{AUMC}_{0-\infty}$ - area under the first moment curve from zero to infinity was calculated using linear trapezoidal rule with equation: $\mathrm{AUMC}_{0 \text {-inf }}=\left[\left(\mathrm{t}_{\mathrm{n}} \times \mathrm{C}_{\mathrm{n}}+\mathrm{t}_{\mathrm{n}+1} \times \mathrm{C}_{\mathrm{n}+1}\right) / 2\right]$ $\left.\times \Delta \mathrm{t}+\mathrm{C}_{\text {last }} / \mathrm{k}_{\mathrm{el}}\right)(29)$.

\section{Statistical analysis}

The traits were tested for departure from normality using the Shapiro-Wilk test. The traits which did not show significant deviation from normality were subject to the heterogeneity of variance test, followed by pooled (heterogeneity of 
variance test $\mathrm{p}$-value $>0.05$ ) or Satterthwaite (heterogeneity of the variance test $\mathrm{p}$-value $<0.05$ ) t-tests to verify the significance of differences between the $\mathrm{I}_{\text {Lap+Clar }}$ and $\mathrm{II}_{\text {Lap }}$. Differences between the $\mathrm{I}_{\mathrm{Lap}+\mathrm{Clar}}$ and $\mathrm{II}_{\mathrm{Lap}}$ in the characteristics which showed significant deviation from normality were tested with the Kruskal-Wallis test. The analysis was performed using capability, t-test and npar 1-way procedures of SAS (SAS Institute Inc. 20022012. The SAS System for Windows version 9.4. Cary, NC, USA). The $90 \%$ confidence intervals for the ratio of geometric means were constructed, except for $t_{\max }$ for which the confidence intervals were based on the difference of medians. For $t_{\max }$ non-parametric Kruskal-Wallis test was used to evaluate significance of the difference between the groups.

\section{RESULTS}

The analytical method was validated according to the guidelines of the European Medicines Agency (EMA) concerning bioanalytical method validation. According to the guidelines, the internal standard may be a structurally similar analog or a stable isotope-labeled compound. The Authors chose erlotinib because it belongs to the same group of drugs as lapatinib (structurally similar analog). Selected IS enabled good precision (coefficient of variation, $\mathrm{CV}<15 \%)$ and accuracy (\%bias $=13 \%)$. The calibration curves ranged within $0.25-5000$ $\mu \mathrm{g} / \mathrm{L}$ with the correlation coefficient $r>0.995$. The lower limit of quantification (LLOQ) was $0.25 \mu \mathrm{g} / \mathrm{L}$. During the sample preparation procedure, the dilution factor ( $\mathrm{DF}=50)$ was applied to quality control

Table 1. Plasma pharmacokinetic parameters for lapatinib following a single oral dose of lapatinib $100 \mathrm{mg} / \mathrm{kg}$.

\begin{tabular}{|c|c|c|c|}
\hline $\begin{array}{l}\text { Pharmacokinetic } \\
\text { parameters }^{\mathrm{a}}\end{array}$ & $\begin{array}{l}\mathrm{I}_{\mathrm{Lap}+\mathrm{Clar}} \\
(\mathrm{n}=6)\end{array}$ & $\begin{array}{c}\mathrm{II}_{\text {Lap }} \\
(\mathrm{n}=6)\end{array}$ & $\begin{array}{c}\mathrm{G}_{\text {mean }} \text { ratio }^{\mathrm{b}} \\
(90 \% \mathrm{CI}) \\
\mathrm{I}_{\text {Lap+Clar }} \\
v s . \mathrm{II}_{\text {Lap }}\end{array}$ \\
\hline $\mathrm{AUC}_{0-\mathrm{t}}(\mu \mathrm{g} \times \mathrm{h} / \mathrm{L})$ & $\begin{array}{c}15627 \pm 6066 \\
(38.8)\end{array}$ & $\begin{array}{c}13866 \pm 6810 \\
(49.1)\end{array}$ & $\begin{array}{c}1.16 \\
(0.75 ; 1.79)\end{array}$ \\
\hline $\mathrm{AUC}_{0-\infty}(\mu \mathrm{g} \times \mathrm{h} / \mathrm{L})$ & $\begin{array}{c}18095 \pm 9394 \\
(51.2)\end{array}$ & $\begin{array}{c}14540 \pm 6495 \\
(44.7)\end{array}$ & $\begin{array}{c}1.21 \\
(0.76 ; 1.94)\end{array}$ \\
\hline $\mathrm{k}_{\mathrm{el}}\left(\mathrm{h}^{-1}\right)$ & $\begin{array}{c}0.085 \pm 0.046 \\
(53.8)\end{array}$ & $\begin{array}{c}0.136 \pm 0.055 \\
\quad(40.2)\end{array}$ & $\begin{array}{c}0.63 \\
(0.36 ; 1.08)\end{array}$ \\
\hline $\mathrm{t}_{1 / 2 \mathrm{kel}}(\mathrm{h})$ & $\begin{array}{c}9.87 \pm 4.26 \\
(43.1)\end{array}$ & $\begin{array}{c}6.66 \pm 4.99 \\
(75.0)\end{array}$ & $\begin{array}{c}1.60 \\
(0.93 ; 2.75)\end{array}$ \\
\hline $\mathrm{Cl} / \mathrm{F}(\mathrm{L} / \mathrm{g} \times \mathrm{h})$ & $\begin{array}{c}0.009 \pm 0.004 \\
(41.3)\end{array}$ & $\begin{array}{c}0.009 \pm 0.003 \\
(39.5)\end{array}$ & $\begin{array}{c}0.98 \\
(0.63 ; 1.54) \\
\end{array}$ \\
\hline $\mathrm{V}_{\mathrm{d}} / \mathrm{F}(\mathrm{L} / \mathrm{g})$ & $\begin{array}{c}0.057 \pm 0.009 \\
(16.1)\end{array}$ & $\begin{array}{c}0.060 \pm 0.031 \\
(51.6)\end{array}$ & $\begin{array}{c}1.06 \\
(0.65 ; 1.74)\end{array}$ \\
\hline $\mathrm{C}_{\max }(\mu \mathrm{g} / \mathrm{L})$ & $\begin{array}{c}2029.17 \pm 276.30 \\
(13.6)\end{array}$ & $\begin{array}{c}1484.63 \pm 324.49 \\
(21.9)\end{array}$ & $\begin{array}{c}1.38 \\
(1.14 ; 1.68)\end{array}$ \\
\hline $\mathrm{t}_{\max }{ }^{\mathrm{c}}(\mathrm{h})$ & $\begin{array}{c}2.5<2-4> \\
(31.7)\end{array}$ & $\begin{array}{c}2.0<1.5-2.0> \\
(27.4)\end{array}$ & $\begin{array}{c}0.5 \\
(-0.45 ; 1.45)\end{array}$ \\
\hline $\mathrm{MRT}_{0-\mathrm{t}}(\mathrm{h})$ & $\begin{array}{c}7.29 \pm 2.04 \\
(28.0)\end{array}$ & $\begin{array}{c}6.50 \pm 1.54 \\
(23.7)\end{array}$ & $\begin{array}{c}1.11 \\
(-0.45 ; 1.44)\end{array}$ \\
\hline $\mathrm{AUMC}_{0-\mathrm{t}}\left(\mu \mathrm{g} \times \mathrm{h}^{2} / \mathrm{L}\right)$ & $\begin{array}{c}123749 \pm 83223 \\
(67.3)\end{array}$ & $\begin{array}{c}85662 \pm 32144 \\
(37.5)\end{array}$ & $\begin{array}{c}1.28 \\
(0.73 ; 2.25)\end{array}$ \\
\hline $\operatorname{AUMC}_{0-\infty}\left(\mu \mathrm{g} \times \mathrm{h}^{2} / \mathrm{L}\right)$ & $\begin{array}{c}249115 \pm 279092 \\
(112.0)\end{array}$ & $\begin{array}{c}118078 \pm 65165 \\
(55.2)\end{array}$ & $\begin{array}{c}1.57 \\
(0.69 ; 3.59)\end{array}$ \\
\hline
\end{tabular}

$\mathrm{k}_{\mathrm{el}}$ - elimination rate constant; $\mathrm{AUC}_{0-\mathrm{t}}$ - area under the plasma concentration-time curve from zero to the time of the last measurable concentration; $\mathrm{AUC}_{0-\infty}-$ area under the plasma concentration-time curve from zero to infinity; $\mathrm{t}_{1 / 2 \mathrm{kel}}$ - elimination half-life; $\mathrm{Cl} / \mathrm{F}$ - clearance; $\mathrm{V}_{\mathrm{d}} / \mathrm{F}$ - volume of distribution; $\mathrm{C}_{\max }-$ maximum plasma concentration; $\mathrm{t}_{\max }$ - time necessary to reach the maximum concentration; $\mathrm{MRT}_{0-\mathrm{t}}$ - mean residence time; $\mathrm{AUMC}_{0-\mathrm{t}}$ - area under the first moment curve from zero to the time of the last measurable concentration; $\mathrm{AUMC}_{0-}$ - area under the first moment curve from zero to infinity; a - arithmetic means \pm standard deviations (CV\%) are shown with CV (\%) in brackets; $b$ - ratio of geometric means $\left(\mathrm{G}_{\text {mean }}\right)$ between groups $(\%)$ with the upper and lower bounds of a $90 \%$ confidence interval $(\mathrm{CI})$ in the brackets; except for $\mathrm{t}_{\max }$, where median differences are presented; $\mathrm{c}-$ these values are expressed as median $<$ range $>$ 


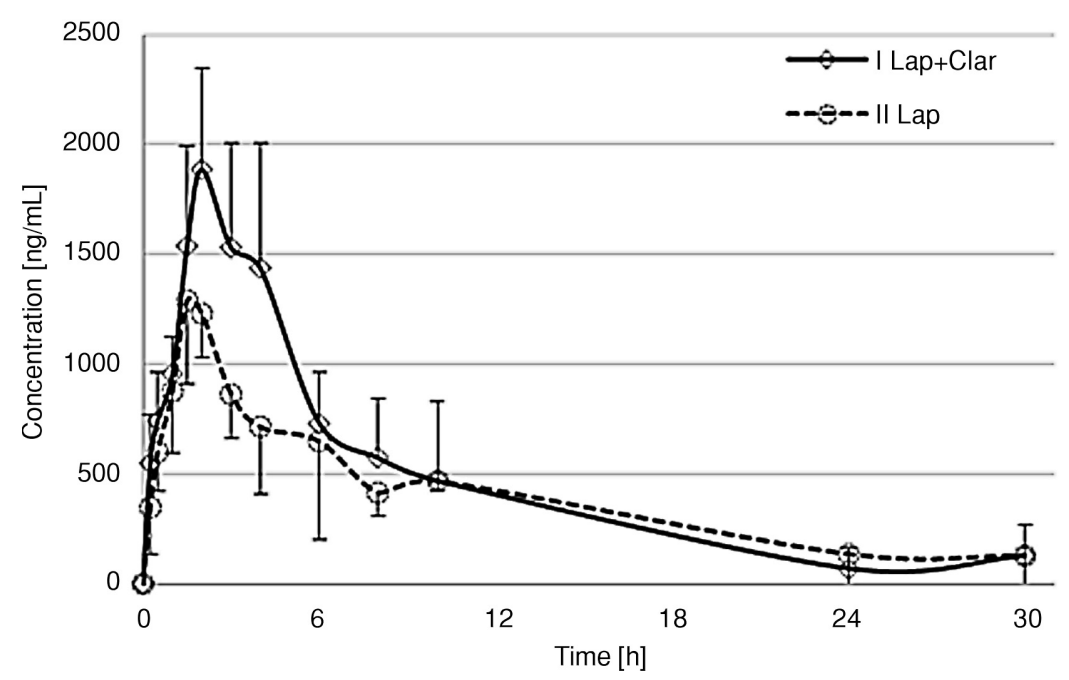

Figure 1. Lapatinib plasma concentration-time profiles in rats receiving lapatinib + clarithromycin $\left(\mathrm{I}_{\text {Lap+Clar }}\right)$ and lapatinib $\left(\mathrm{II}_{\mathrm{Lap}}\right)$

samples and plasma samples. As a result, the concentrations of the compound were 50 times lower than those in undiluted rat plasma. In 2 samples after $30 \mathrm{~h}$, the levels of lapatinib in the control group were below the LLOQ. Matrix factor (MF) was used as a quantitative measure to determine the matrix effect. The variability of the IS-normalized MF from six lots of matrix, measured by coefficient of variation (CV\%), in our method was less than $15 \%$.

All the data were expressed as the mean value \pm standard deviation (SD). The groups of rats did not differ significantly in terms of body mass. The arithmetic mean plasma concentrations of lapatinib after its administration to the groups are shown in Figure 1. The figure does not represent a model fit but visualization of raw data flow. The main pharmacokinetic parameters from non-compartmental methods are summarized in Table I. Clarithromycin significantly increased lapatinib $\mathrm{C}_{\max }$ by $36 \%(\mathrm{p}=0.0107)$. When lapatinib and clarithromycin were coadministered, the $\mathrm{AUC}_{0-8}$ increased from 14540.25 to $18095.03 \mu \mathrm{g} \times \mathrm{h} / \mathrm{mL}$, but there was no statistical significance $(\mathrm{p}=0.4634)$. In the group of rats receiving clarithromycin and lapatinib, $\mathrm{t}_{1 / 2 \mathrm{kel}}$ was longer when compared to the group receiving lapatinib, but there was no statistical significance $(\mathrm{p}=0.1093)$. No statistically significant differences were revealed for area under the plasma concentration-time curve from zero to the time of the last measurable concentration $(\mathrm{p}=0.6464)$, area under the plasma concentration-time curve from zero to infinity ( $p=0.4634)$, clearance $(p=0.8722)$, volume of distribution $(p=$ $0.8008)$, elimination rate constant $(p=0.1103)$, elimination half-life $(\mathrm{p}=0.1093)$, mean residence time $(p=0.4678)$, area under the first moment curve $(p=0.5218)$, area under the first moment curve from zero to infinity $(\mathrm{p}=0.3367)$.

\section{DISCUSSION}

The CYP3A4 isoenzyme participates in the biotransformation of various drugs, which may additionally exhibit inductive or inhibitory effect on the activity of this isoenzyme. Phenytoin, carbamazepine, and rifampicin are well-known enzyme inducers, whereas erythromycin, clarithromycin, fluconazole, ketoconazole, and indinavir are enzyme inhibitors (30). The experiments on rats showed that clarithromycin may affect the pharmacokinetics of lapatinib. It is a first study describing in vivo interaction between lapatinib, new tyrosine inhibitor and the broadly used macrolide antibiotic. A single administration of clarithromycin and lapatinib resulted in the extension of $\mathrm{t}_{\max }(2.83 \mathrm{vs} .2 .00 \mathrm{~h})$ for tyrosine kinase inhibitor and a significant increase in the mean $\mathrm{C}_{\max }$, as compared with the group which received lapatinib only (2029.17 vs. $1484.63 \mu \mathrm{g} / \mathrm{L})$. It is likely that the changes were caused by the inhibitory effect of clarithromycin on P-gp and CYP3A4. In consequence, the drug absorption increased, whereas lapatinib metabolism decreased. Moreover, Aueviriyavit et al. revealed that clarithromycin exhibited markedly weaker mechanismbased inactivation effects on CYP3A activity in rat liver microsomes compared to human liver microsomes, therefore the effect in our study can be 
enhanced in humans (31). Apart from that, due to the fact that lapatinib is an inhibitor of P-gp, where clarithromycin is the substrate, the concentration of the antibiotic in the blood may increase. In consequence, its pharmacological effect and interaction potential will increase. Moreover, the effect of DMSO on lapatinib pharmacokinetics can not be excluded, especially for drug metabolism. DMSO is a cheap and broadly used solvent and carrier for many drugs. In the experiment, lapatinib was dissolved in $1 \mathrm{~mL}$ DMSO and administered directly into the animal stomach. DMSO may inhibit CYP1A2, 2C8/9, 2 C19, 2D6, 2E1 and CYP3A4 in various degree (32), but DMSO did not alter plasma creatinine concentrations in rat and in small doses did not have influence on oral drug absorption (33, 34). Because all rats received the same amount of the solvent, observed differences in lapatinib concentrations between analyzed two groups of animals were not caused by DMSO.

The clinical significance of the potential increase in the $\mathrm{C}_{\max }$ of lapatinib, when administered to patients in combination with CYP3A4 inhibitors, has not been clearly defined yet. The similar experiment which concerned potential interaction between antibiotic and tyrosine kinase inhibitor proved that antibiotics like ciprofloxacin (fluoroquinolone) can lead to increased concentrations of sunitinib in the cerebrospinal fluid in rabbits. Probably reason of that is inhibition CYP3A4 by the ciprofloxacin (35). Like other tyrosine kinase inhibitors, lapatinib is a drug with a wide therapeutic range. Investigations have not revealed a relationship between lapatinib plasma concentrations and the occurrence of side effects (SE). The most common SE of lapatinib is diarrhea, which causes dehydration and was observed in nearly half of the patients treated with the drug. The occurrence of such symptoms as: moderate to severe diarrhea, severe nausea or vomiting, and severe cramping, significantly reduces the patient's quality of life and causes the need to stop taking the drug until recovery and then reduce its dose (36). However, it is known that the development of diarrhea is related to the oral dose rather than the drug plasma concentration (37). The relation between lapatinib concentration and hepatotoxicity may be different. It is a frequent adverse effect of this tyrosine kinase inhibitor, which causes discontinuation of treatment. Liver damage is the result of the inhibition of $\mathrm{ABCB} 1$ transporters by lapatinib. It increases the toxicity of the compounds which are substrates of ABCB1 transporters, such as paclitaxel and doxorubicin (38). Due to the fact that lapatinib is a substrate for the P-gp transport protein, it cannot be ruled out that a higher concentration of the drug combined with clarithromycin, which is a CYP3A4 and P-gp inhibitor, will not increase the hepatotoxicity of the anticancer therapy (39). Limitation of the study is single dose design. The in vivo inhibitory effect caused by clarithromycin could be more prominent after multiple dosing. Future research directions include therapeutic drug monitoring in patients who are treated with lapatinib and the macrolide antibiotics (clarithromycin and erythromycin) to confirm or exclude clinical significance of the interaction. Additionally, because of increased risk of hepatotoxicity after concomitant use of the tyrosine kinase inhibitor and clarithromycin, monitoring of liver function should be considered.

\section{CONCLUSION}

Single oral administration of clarithromycin significantly increased concentration of lapatinib in rats, therefore caution should be taken during concomitant treatment with this macrolide and the tyrosine kinase inhibitor in patients.

\section{Funding}

The study was financed with the academic grant of the Poznan University of Medical Sciences (grant No. 502-05-33114230-70009). The funding source did not affect any part of the study, preparation or submission of the manuscript.

\section{Conflicts of interest}

Karbownik Agnieszka, Porażka Joanna, Łuczak Anna, Teżyk Artur, Grabowski Tomasz, Wolc Anna, Grześkowiak Edmund, Szałek Edyta have no conflict of interest.

\section{Ethics approval}

The research was approved by the Local Ethical Committee for animal experiments (54/2017). All procedures performed in studies involving animals were in accordance with the ethical standards of the institution at which the studies were conducted.

\section{REFERENCES}

1. Teo Y.L., Ho H.K., Chan A.: Br. J. Clin. Pharmacol. 79, 2 (2015).

2. van Leeuwen R.W., van Gelder T., Mathijssen R.H., Jansman F.G.: Lancet Oncol. 15, 8 (2014). 
3. https://www.ema.europa.eu/documents/product-information/tyverb-epar-product-information_en-0.pdf (accesssed on 05. 11. 2018).

4. Ferlay J., Soerjomataram I., Ervik M., Dikshit R., Eser S. et al.: Int. J. Cancer. 1, 136 (2015).

5. Polli J.W., Humphreys J.E., Harmon K.A., Castellino S., O'Mara M.J. et al.: Drug Metab. Dispos. 36, 4 (2008).

6. Wright A.J., Gomes T., Mamdani M.M., Horn J.R., Juurlink D.N.: CMAJ. 183, 3 (2011).

7. Zhanel G.G., Dueck M., Hoban D.J., Vercaigne L.M., Embil J.M. et al.: Drugs. 61, 4 (2001).

8. Amsden G.W., Kuye O., Wei G.C.: J. Clin. Pharmacol. 42, 4 (2002).

9. Eljaaly K., Alshehri S., Bhattacharjee S., AlTawfiq J.A., Patanwala A.E.: Clin. Microbiol. Infect. 11 (2018). DOI: 0.1016/j.cmi.2018.08. 002.

10. Kaleem Z., Khan J.A., Mushtaq Z., Altaf S., Javed I.: Pak. J. Pharm. Sci. 31, 3 (2018).

11. Oh E.S., Choi C., Kim C.O., Kim K.H., Kim Y.N. et al.: J. Clin. Pharm. Ther. 42, 6 (2017).

12. Gorski J.C., Jones D.R., Haehner-Daniels B.D., Hamman M.A., O’Mara E.M Jr. et al.: Clin. Pharmacol. Ther. 64, 2 (1998).

13. Cheung K.K., Senior P.A.: Clin. Diabetes. Endocrinol. 2, 2 (2016).

14. Pea F., Cojutti P., Tursi V., Livi U., Baraldo M.: Transpl. Infect. Dis. 17, 6 (2015).

15. Qiu X.H., Shao J.J., Mei J.G., Li H.Q., Cao H.Q.: Acta Haematol. 135, 2 (2016).

16. Scott P.J., Shao X., Desmond T.J., Hockley B.G., Sherman P. et al.: ACS Med. Chem. Lett. 7, 8 (2016).

17. Hung I.F.N., To K.K.W., Chan J.F.W., Cheng V.C.C., Liu K.S.H. et al.: Chest. 151, 5 (2017).

18. Oh E.S., Choi C., Kim C.O., Kim K.H., Kim Y.N. et al.: J. Clin. Pharm. Ther. 42, 6 (2017).

19. Mishima E., Maruyama K., Nakazawa T., Abe T., Ito S.: Intern. Med. 56, 13 (2017).

20. Page S.R., Yee K.C.: Intern. Med. J. 44, 7 (2014).

21. Moj D., Hanke N., Britz H., Frechen S., Kanacher T. et al.: AAPS J. 19, 1 (2017).
22. Akiyoshi T., Ito M., Murase S., Miyazaki M., Guengerich F.P. et al.: Drug Metab. Pharmacokinet. 28, 5 (2013).

23. Bogaards J.J., Bertrand M., Jackson P., Oudshoorn M.J., Weaver R.J. et al.: Xenobiotica. 30, 12 (2000).

24. Lin F., Wang S., Zhou Y., Wu C., Zou H. et al.: Pharmacology 95, 3 (2015).

25. Darbalaei S., Zhang X., Wang N., Qin Y., Han X. et al.: Pharmazie 1, 73 (2018).

26. Kotegawa T., Laurijssens B.E., Von Moltke L.L., Cotreau M.M., Perloff M.D. et al.: J. Pharmacol. Exp. Ther. 302, 3 (2002).

27. Götze L., Hegele A., Metzelder S.K., Renz H., Nockher W.A.: Clin. Chim. Acta 18, 413 (2012).

28. Guideline on bioanalytical method validation. European Medicines Agency (EMEA/CHMP/ EWP/192217/2009 Rev.1 Corr. 2**). London, 21 July 2011.

29. Gibaldi M., Perrier D.: Pharmacokinetics. Swarbrick J. Ed. pp. 45-111, Dekker, New York 1982.

30. Medina P.J., Goodin S.: Clin. Ther. 30, 8 (2008).

31. Aueviriyavit S., Kobayashi K., Chiba K.: Drug Metab. Pharmacokinet. 25, 1 (2010).

32. Chauret N., Gauthier A., Nicoll-Griffith D.A.: Drug Metab. Dispos. 26, 1 (1998).

33. Ali B.H., Mousa H.M.: Hum. Exp. Toxicol. 20, 199 (2001).

34. Passananti G.T., Shively C.A., Vesell E.S.: Ann. N. Y. Acad. Sci. 27, 243 (1975).

35. Szałek E., Karbownik A., Sobańska K., Płotek W., Grabowski T.: Acta Pol. Pharm. 71, 4 (2014).

36. Jamil M.O., Rizwan M., Carpenter J.T.: J. Clin. Oncol. 33, 29 (2015).

37. Burris H.A., Taylor C.W., Jones S.F., Koch K.M., Versola M.J. et al.: Clin. Cancer Res. 15, 21 (2009).

38. Dai C., Ma S., Wang F., Zhao H., Wu X. et al.: Oncotarget. 6, 19 (2015).

39. Lam A., Hoang J.D., Singleton A., Han X., Bleier B.S.: Int. Forum Allergy Rhinol. 5, 6 (2015)

Received: 21.11 .2018 